\title{
The Influence of Soil Moisture in The Unsaturated Zone on the Heat Loss from Buildings via the Ground
}

\author{
HANS JANSSEN ${ }^{1}$, JAN CARMELIET AND Hugo HENS \\ Department of Civil Engineering \\ Laboratory of Building Physics \\ Catholic University of Leuven \\ Kasteelpark Arenberg 51 \\ 3001 Leuven \\ Belgium
}

\begin{abstract}
In calculations of building heat loss via the ground, the coupling with soil moisture transfer is generally ignored, an important hypothesis which will be falsified in this paper. Results from coupled simulations - coupled soil heat and moisture transfer equations and complete surface heat and moisture balances - are compared to results from linear simulations. It is shown that the coupled calculations give notably higher heat losses. Surface temperature, the driving force for heat loss via the ground, is identified as a first important source for these deviations: it is shown that while the averages of the surface temperature are almost equal in coupled and linear calculations, the amplitude in the coupled simulation is considerably higher. A further study reveals that variation of the thermal properties with moisture content also contributes partially to the observed differences. Transfer and storage of sensible heat linked to moisture in the liquid phase was shown to be the last important influencing factor.
\end{abstract}

\section{KEYWORDS}

Foundation heat loss, coupled heat and moisture transfer, soil thermal properties, surface heat and moisture balance, evaporation, advective heat transfer.

\section{INTRODUCTION}

\section{Heat Loss from Buildings via the Ground}

The last few decades, a distinct evolution to a more sustainable use of energy is taking place. As the heating and cooling of buildings forms a substantial part of the global energy budget, the building industry - and building science - has not been left unaffected. One of the more important measures in this field is the ongoing improvement of the insulating quality of the building envelope.

However, most of the efforts have been concentrated mainly on the above grade building parts as walls and roofs, since they initially posed the biggest potential. Consequently, the heat loss

\footnotetext{
${ }^{1}$ Author to whom correspondence should be addressed.

Tel.: +32 163213 45, Fax: +32 163219 80, E-mail: hans.janssen@bwk.kuleuven.ac.be.
} 
Postprint: Janssen H, Carmeliet J, Hens $\mathrm{H}$ 2002. The influence of soil moisture in the unsaturated zone on the heat loss from buildings via the ground, Journal of Thermal Envelope and Building Science, 25:275-296.

doi: $10.1177 \% 2 F 0075424202025004683$

from buildings via the ground is gaining importance. At present, foundation heat loss can no longer be considered a less important part in the overall building heat loss (Hagentoft, 1988). The problem of building heat loss via the ground is intrinsically more complex than the heat transfer through above grade building parts. The more significant reasons for this are (1) heat loss via the ground is basically a multidimensional phenomenon; (2) the large thermal mass of the ground domain necessitates nonstationary calculations; and (3) the variation in geometries and insulating strategies leads to a large number of parameters to consider (Anderson, 1991). Despite this relative complexity of the problem, a vast amount of research on foundation heat loss has already been performed. The earliest publications stem from the forties: at that time, Houghten et al. (1942) performed the first - documented - measurements on heat losses from basement walls and floors. Some years later, Bareither et al. (1948), and Dill et al. (1945) reported on measurements on slabs. Recently, the methods of Hagentoft (1988) and Anderson (1991, 1993) have been combined to form the European Standard EN ISO 13370: Thermal performance of buildings - Heat transfer via the ground-Calculation methods. At present, proper calculation methods exist for most foundation geometries and insulation strategies.

\section{Influence of soil moisture on foundation heat losses to the ground}

Although, the research field on building heat loss via the ground knows one major shortfall: in most cases, the coupling between soil heat transfer and soil moisture transfer is not taken into account. Soil thermal conductivity and thermal capacity are generally considered constant in space and time, meaning the dependence on soil moisture content is ignored. Furthermore, in most cases it is assumed that the heat transfer at the soil surface is governed solely by the air temperature, usually in combination with a constant heat transfer coefficient. Moreover, only thermal conduction is taken into account as soil heat transfer mechanism.

Nevertheless, soil moisture and soil heat transfer interact through various mechanisms: (1) the thermal conductivity and the thermal capacity of soil are highly dependent on soil moisture content, (2) evapo(transpi)ration forms an integral part of the heat balance at the surface of the ground, and (3) the transfer, storage and phase change of moisture in the liquid and gaseous phase cause a simultaneous transfer and storage of sensible and latent heat. The latent heat of fusion involved in the formation of ice does also affect the transfer of heat in soils. However, since modelling this particular phenomenon is of great complexity, it has not been included in this study. The results presented here can hence considered valid only for temperate climates, where soil frost occurs only minimally.

Surely, the specific field of the influence of soil moisture on building heat loss via the ground has not been left entirely unattended. Farouki (1982) collected experimental data on thermal conductivity and capacity of soil. The thermal conductivity of dry and wet sands can differ up to a factor ten, of dry and wet loams up to a factor five. The variance in thermal capacity is less manifest but it still doubles or triples from dry to wet state. Complimentarily, Matsumoto and Iwamae (1988) computed the one-dimensional transport of heat and moisture in soil. A substantial variation of the soil moisture content was recorded for the first few meters under the surface.

Bahnfleth and Pedersen (1990) examined the effect of including solar and long wave radiation and potential evaporation in the heat balance on soil temperature and building heat loss. In the ground domain, conduction was assumed the sole heat transfer mechanism, with constant thermal properties. The foundation heat losses changed notably when radiation and evaporation were included. Results of Bharadwaj and Bansal (1981) and Gupta et al (1981), investigating the effect of thermal and hygric boundary conditions on soil temperature, confirm these findings. 
Postprint: Janssen H, Carmeliet J, Hens $\mathrm{H}$ 2002. The influence of soil moisture in the unsaturated zone on the heat loss from buildings via the ground, Journal of Thermal Envelope and Building Science, 25:275-296.

doi: $10.1177 \% 2 F 0075424202025004683$

In a very limited study Shen (1986) calculated the two-dimensional coupled heat and moisture transfer in soil near a basement wall. The fully coupled equations for soil heat and moisture transfer were applied, but the heat and moisture balances at the surface were kept very simple. Both a sand and a loam soil were applied for the calculations, which were performed for two periods of 15 days, one in winter and one in summer. Although this limited set of simulation results remains insufficient to allow general conclusions, it is shown that use of uncoupled or coupled equations for soil heat and moisture transfer results in notably different temperature and moisture content fields, and leads to significant differences in the basement wall heat loss. More recently, Rees et al. (2001) analysed the influence of water table height on the heat loss from earth-contact structures with the coupled equations for soil heat and moisture transfer. Similarly, very simple heat and moisture surface balances were applied. The moisture content in the ground domain was assumed to be in gravitational equilibrium, with the height of the water table as sole variable. No moisture flow was thus considered. As only steady-state heat losses were calculated, the influence of soil moisture content on soil thermal conductivity was the only coupling effect taken into account. Though this makes the results quite restrictive, it was clearly demonstrated that the influence of soil moisture on building heat losses via the ground is not negligible, and deserves further attention.

Ogura et al. $(1995,1998)$ applied the fully coupled soil heat and moisture transfer equations and the complete heat and moisture surface balances to investigate the hygrothermal climate in unconditioned underground spaces. As the calculation object were unconditioned spaces, the response of the indoor climate to the transfer of heat and moisture in soil was emphasised, and not the heat loss from the underground structure. Nevertheless, these publications present the first fully coupled analysis of hygrothermal interaction between buildings and the ground. In this paper, a fully coupled analysis of the influence of soil moisture on building heat loss via the ground is performed. The influence of soil moisture in the unsaturated zone will be stressed, hence water flow below the water table will not be taken into account. To that aim, the heat loss of an insulated basement has been calculated - twodimensionally- with a fully coupled method, both for a sand and for a loam soil: the coupled equations for soil heat and moisture transfer and the complete heat and moisture balances at the soil surface, driven by atmospheric boundary conditions, are applied. In a second calculation, a linear approach is applied: moisture contents in the soil were constant, with thermal conduction as heat transfer mechanism and convection, driven by the air temperature, at the soil surface. In a variant, solar and long wave radiation were added to the surface heat balance, to simulate the use of "equivalent temperature" in the heat balance at the surface.

Results are compared, and explanations for the observed deviations are sought in two distinct directions: differences in the resulting basement heat loss can be caused (1) by differences in surface temperature, and (2) by differences in the coupling between heat and moisture transfer in soil. To distinguish the important factors in this interaction between the transfer equations, additional simulations with varying degree of coupling are performed.

\section{MODEL FOR COUPLED HEAT AND MOISTURE TRANSFER IN SOIL}

\section{Coupled heat and moisture transfer in soil}

Milly (1980) adopted the Philip and de Vries (1957) and de Vries (1958) equations for coupled heat and moisture transfer in porous materials and reformulated them to obtain matric potential $\psi$ rather than moisture content $\theta$ as independent variable (Equation (1): heat transfer; Equation (2): moisture transfer): 
Postprint: Janssen H, Carmeliet J, Hens $\mathrm{H}$ 2002. The influence of soil moisture in the unsaturated zone on the heat loss from buildings via the ground, Journal of Thermal Envelope and Building Science, 25:275-296.

doi: $10.1177 \% 2 F 0075424202025004683$

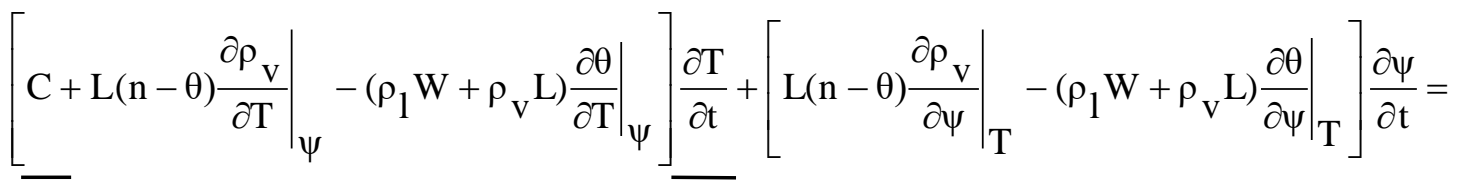

$$
\begin{aligned}
& \nabla\left[\left(\lambda^{*}+\rho_{1} D_{T V}\right) \nabla \underline{T}+\rho_{1} L_{\Psi v} \nabla \psi\right]-c_{1} q_{m} \nabla T \\
& {\left[\left.\left(1-\frac{\rho_{\mathrm{V}}}{\rho_{1}}\right) \frac{\partial \theta}{\partial \psi}\right|_{T}+\left.\frac{\mathrm{n}-\theta}{\rho_{1}} \frac{\partial \rho_{\mathrm{V}}}{\partial \psi}\right|_{\mathrm{T}}\right] \frac{\partial \psi}{\partial \mathrm{t}}+\left[\left.\left(1-\frac{\rho_{\mathrm{V}}}{\rho_{1}}\right) \frac{\partial \theta}{\partial \mathrm{T}}\right|_{\psi}+\left.\frac{\mathrm{n}-\vartheta}{\rho_{1}} \frac{\partial \rho_{\mathrm{V}}}{\partial \mathrm{T}}\right|_{\psi}\right] \frac{\partial \mathrm{T}}{\partial \mathrm{t}}=} \\
& \left.\left.\overline{\nabla[(\mathrm{K}}+\mathrm{D}_{\psi \mathrm{v}}\right) \nabla \psi+\mathrm{D}_{\mathrm{Tv}} \nabla \mathrm{T}\right]+\frac{\partial \mathrm{K}}{\partial \mathrm{z}}
\end{aligned}
$$

The left sides of Equations (1) and (2) describe respectively the storage of heat and moisture. Moisture storage in the porous medium is possible by changes in matric potential as well as by changes in temperature, as both moisture content $\theta$ and vapour density $\rho_{\mathrm{v}}$ depend on matric potential and temperature. Similarly, heat storage can result from changes in temperature as well as in matric potential. The right sides of Equations (1) and (2) describe the transport of heat and moisture. Transfer of moisture is caused by gradients both in matric potential and temperature. As vapour density $\rho_{\mathrm{v}}$ depends on temperature $\mathrm{T}$, water vapour transfer can be induced by temperature gradients. The last term in Equation (2) indicates moisture transfer by gravity. The heat transfer is also governed by gradients in temperature and matric potential. In Equation (1), the last term represents the advection of sensible heat by moisture transfer. The two terms multiplying the temperature gradient in Equation (1) - thermal conductivity $\lambda^{*}$ and latent heat transfer by thermal vapour diffusion $\rho_{1} \mathrm{LD}_{\mathrm{Tv}}$ - are not strictly additive: both effects interact, resulting in an effective thermal conductivity $\lambda$ (de Vries, 1958). Since no measurement technique allows to differentiate between both, measured thermal conductivities will always embody latent heat transfer by thermal vapour diffusion. Even linear calculations of ground heat loss will hence include this particular coupling effect. When "conduction" is referred to in this article, thus the effective thermal conductivity $\lambda$ will be applied, implicitly including $\rho_{\mathrm{l}} \mathrm{LD}$ Tv.

The underlined parts of Equations (1) and (2) represent respectively the second law of Fourier and the Richards equation. The second law of Fourier is generally applied for soil temperature calculations. The Richards equation is commonly used for soil moisture transfer calculations. The differences resulting from the use of the uncoupled and the coupled equations in onedimensional simulations have been demonstrated extensively by Janssen et al. (1999).

In soil science, empirical and theoretical models are generally used to describe the material properties, as measured data are difficult to obtain. An in depth elaboration on those models can be found in Milly (1980) and will, for reasons of brevity, not be treated here.

\section{Heat and moisture balance at the soil surface}

For the heat and moisture balance at the soil surface, a bare soil surface is assumed, which is not irrigated. Hence, evapotranspiration and root water uptake by plants take no part in the surface transfer processes. The moisture balance at the surface thus includes precipitation $\mathrm{P}$ and evaporation $\mathrm{E}$ (Equation (4)), while the heat balance comprises sensible heat $\mathrm{H}$, solar and long wave radiation $\mathrm{R}_{\mathrm{t}}$, and the transfer of sensible and latent heat by evaporation LE and precipitation HP (Equation (3)):

$$
\mathrm{q}_{\mathrm{h}, \mathrm{se}}=\mathrm{H}+\mathrm{R}_{\mathrm{t}}+\mathrm{LE}+\mathrm{HP}
$$


Postprint: Janssen H, Carmeliet J, Hens $\mathrm{H}$ 2002. The influence of soil moisture in the unsaturated zone on the heat loss from buildings via the ground, Journal of Thermal Envelope and Building

$$
\mathrm{q}_{\mathrm{m}, \mathrm{se}}=\rho_{1}(\mathrm{E}+\mathrm{P})
$$

Evaporation is calculated as:

$$
\mathrm{E}=\frac{\left(\rho_{\mathrm{v}, \mathrm{e}}-\rho_{\mathrm{v}, \mathrm{se}}\right)}{\mathrm{r}_{\mathrm{a}}}
$$

in which $r_{a}$ is the aerodynamic resistance:

$$
\mathrm{r}_{\mathrm{a}}=\frac{\left[\ln \left(\mathrm{z}_{\mathrm{a}} / \mathrm{z}_{0}\right)\right]^{2}}{\mathrm{k}^{2} \mathrm{~W}_{\mathrm{s}} \phi}
$$

$\phi$ is an instability factor, which incorporates the influence of the turbulence and stability of the atmosphere. It depends mainly on the wind speed and the temperature and vapour content differences between surface and atmosphere, a complex relation given by Anderson (1976).

The transfer of sensible heat $\mathrm{H}$ - convection - is to be calculated by:

$$
\mathrm{H}=\frac{\rho_{\mathrm{a}} \mathrm{c}_{\mathrm{a}}\left(\mathrm{T}_{\mathrm{e}}-\mathrm{T}_{\mathrm{se}}\right)}{\mathrm{r}_{\mathrm{a}}}
$$

The net amount of incoming radiation $\mathrm{Rt}$ is equal to:

$$
\mathrm{R}_{\mathrm{t}}=(1-\alpha) \cdot \mathrm{R}_{\text {glob }}+\mathrm{R}_{\text {sky }}-\mathrm{R}_{\mathrm{g}}
$$

and surface emission is calculated as:

$$
\mathrm{R}_{\mathrm{g}}=\sigma \cdot \varepsilon_{\mathrm{g}} \cdot \mathrm{T}_{\mathrm{g}}^{4}
$$

The transfer of latent heat generated by evaporation LE is equal to:

$$
\mathrm{LE}=\left(\mathrm{L}+\mathrm{c}_{\mathrm{p}}\left(\mathrm{T}_{\mathrm{se}}-\mathrm{T}_{0}\right)\right) \mathrm{E}
$$

and the enthalpy flow induced by precipitation HP can be computed as:

$$
\mathrm{HP}=\mathrm{c}_{1}\left(\mathrm{~T}_{\mathrm{e}}-\mathrm{T}_{0}\right) \mathrm{P}
$$

\section{CALCULATION OBJECT AND CLIMATE DATA}

As an exemplary case study, the heat loss from an infinitely long insulated basement, with an external depth and width of $2.5 \mathrm{~m}$ by $10 \mathrm{~m}$, is studied. As stated by Hagentoft (1988), the heat transfer process through the basement structure can be assumed stationary. This allows to use a thermal transmittance, which is taken $0.7 \mathrm{~W} / \mathrm{m}^{2} \mathrm{~K}$ for both the cellar wall and floor. The foundation structure $-15 \mathrm{~cm}$ of concrete and $5 \mathrm{~cm}$ of insulation - should hence not be modelled explicitly. Symmetry is considered for all calculations: only half of the basement is modelled. The modelled half of the ground domain has a total width of $20 \mathrm{~m}$ and a depth of $15 \mathrm{~m}$. These dimensions were determined based on guidelines stated in the EN ISO 13370. The geometry and its discretisation is shown in Figure 1.

Based on the classification scheme defined by the USDA - the United States Department of Agriculture - the centres of the polygons enclosing respectively all sandy and all loamy soils have been taken as typical sand (69\% sand, $15 \%$ silt, $16 \%$ clay) and loam (37\% sand, $38 \%$ 
Postprint: Janssen H, Carmeliet J, Hens $\mathrm{H}$ 2002. The influence of soil moisture in the unsaturated zone on the heat loss from buildings via the ground, Journal of Thermal Envelope and Building Science, 25:275-296.

doi: $10.1177 \% 2 F 0075424202025004683$

silt, $25 \%$ clay). Hydraulic parameters for both soils have been obtained with ROSETTA (Schaap et al., 1998), a prediction program - based on neural networks - for soil hydraulic parameters. For the thermal properties, $80 \%$ of the sand, $35 \%$ of the silt and $5 \%$ of the clay was considered quartz (Tarnawski et al, 1997), the remaining part is assumed less conductive. An overview of the most important material properties is given in Figure 2 (where " $\mathrm{pF}$ " is defined as the logarithm of the absolute value of matric potential $\psi$ ).

In all calculations, climate data are taken from a TRY weather file for Essen (Germany). This file contains hourly averages for air temperature, direct and diffuse short wave radiation, long wave sky radiation, wind speed, relative humidity and vertical rain. Daily averages were used here, as both Hagentoft (1988) and Bahnfleth (1990) observed "within-the-day" variations of the climatic values to have an insignificant effect on foundation heat loss. Preliminary results show that this assumption still holds when taking complete surface heat and moisture balances into account. Monthly averages of air temperature and monthly amounts of rain for the Essen (Germany) climate are depicted in Figure 3. The resulting variation of soil temperature and soil moisture content in a $15 \mathrm{~m}$ deep (=depth of watertable) column of soil are shown as monthly averages in Figure 4.

Figure 4 clearly demonstrates the difference between the transfer of heat and moisture in soil: while the temperature amplitude is dampened quite quickly, the moisture content variations penetrate almost to the bottom of the soil domain. Figure 4 also illustrates the differences in behaviour caused by the kind of soil: while the temperature profiles are more or less similar, the average moisture content is lower in the sandy soil, which has a higher permeability.

\section{CALCULATIONS AND RESULTS}

\section{Degree of coupling and boundary conditions}

In calculation A the heat loss from the basement is calculated with the fully coupled equations for soil heat and moisture transfer and the complete heat and moisture balances at the surface. For calculation B, the moisture content was kept at the year-averaged moisture content of A. Only the variation with time was omitted, the spatial variation was kept. No moisture transfer was hence included, and effective conduction - with use of $\lambda$ - was the only thermal transfer mechanism involved. At the surface, the air temperature governed the solely convective heat transfer (term $\mathrm{H}$ in Equation (3)). In calculation $\mathrm{C}$, similar restraints on the transfer equations were applied, but the heat balance at the surface comprised convection $(\mathrm{H})$ and solar and long wave radiation $\left(\mathrm{R}_{\mathrm{t}}\right)$, this way simulating the use of the "equivalent temperature" as boundary condition. Calculation A will be considered the reference calculation, calculations B and C are common simplifications.

In all calculations, the basement was assumed to be fully conditioned: the internal temperature was kept at $20^{\circ} \mathrm{C}$. The basement wall and floor were considered impermeable, as were the two planes that limit the ground domain vertically. At the bottom, a watertable was assumed present, and the moisture content was kept at saturation. No ground water flow beneath the water table was considered. The two vertical bounding planes were taken as adiabatic. At the bottom, only enthalpy transfer by moisture flow was allowed.

All calculations covered a period of fifteen years, only the results from the last year will be retained for analysis here. The average difference in heat losses, for both walls and floors, between year 15 and 14 was in all cases less than $0.02 \%$. 
Postprint: Janssen H, Carmeliet J, Hens $\mathrm{H}$ 2002. The influence of soil moisture in the unsaturated zone on the heat loss from buildings via the ground, Journal of Thermal Envelope and Building Science, 25:275-296.

doi: $10.1177 \% 2 F 0075424202025004683$

\section{Calculation results}

Figure 5 presents the heat losses from the insulated basement, located respectively in the sand and the loam soil. The heat losses through the basement wall and floor are marked separately. The average daily heat losses for wall and floor have been collected in Table 1a, net energy demands for the heating season (Oct 1 till Mar 31) in Table $1 b$.

As can be observed in Figure 5 and in Tables 1a and 1b, particular deviations exist between the results from different calculations. All in all calculation $\mathrm{C}$ gives the lowest heat losses, while calculation A results in the highest values. When comparing the heating season energy demand for the complete basement: differences with the reference calculation A were $-9 \%$ (B) and $-14 \%$ (C) for the sand soil, and $-9 \%(B)$ and $-15 \%(C)$ for the loam soil. As shown in Figure 5, the differences between the $\mathrm{A}, \mathrm{B}$ and $\mathrm{C}$ calculations are most prominent for the floor losses, while the curves of the wall heat losses tend to overlap in particular areas.

\section{ANALYSIS OF THE RESULTS}

The most important observation made in the previous paragraph are the distinct differences between the results from the calculations $\mathrm{A}, \mathrm{B}$ and $\mathrm{C}$. In this paragraph, possible reasons for the deviations will be scrutinised. These reasons are to be sought in two fields:

- driving force: variations in composition of the heat balance at the surface may lead to different soil surface temperatures, and hence to different foundation heat losses.

- heat transfer in the ground domain: the inclusion of moisture storage and transfer in the heat transfer equation may produce alternative mechanisms for heat storage and transfer.

To distinguish between both items, the soil surface temperatures and heat losses from the basement wall and floor have been approximated by harmonic functions, characterised by an average, an amplitude and a phase shift. The resulting averages and amplitudes are collected in Table $2 \mathrm{a}$ for the surface temperatures. The steady state thermal permeance U' was derived as the quotient of the averages of heat flow and of temperature difference - between basement air and outside surface -, the periodic thermal permeance $L_{p}{ }^{6}$ as the quotient of the amplitudes of heat flow and of temperatures difference - between basement air and outside surface -. These are brought together in Table $2 \mathrm{~b}$. Note that the outside surface temperature, and not air temperature, is used here for the calculation of the thermal permeances, since use of the air temperature would conceal deviations due to differences in the surface heat balances, and possibly lead to incorrect interpretations. If, for example, the outside air temperature was used for the calculation of $\mathrm{U}$ ' for calculations $\mathrm{B}$ and $\mathrm{C}, \mathrm{C}$ would seemingly result in a lower U'-value. Differences between B and C are however not caused by differences in thermal permeance of the ground domain, but by different surface temperatures. These differences would however not be reflected by use of the air temperature in the calculation of $U$ ' and $L_{p}$ '.

\section{Surface temperatures}

Kusuda and Achenbach (1965) and Givoni and Katz (1985) measured that the average soil surface temperature is usually almost equal to the average air temperature while the amplitude is generally slightly larger than that of the air temperature. They conclude that for a correct estimation of soil surface temperatures, solar/long wave radiation and evaporation should be taken into account. Looking at the calculation results in Table 2a, calculations $\mathrm{C}$ appear not to reflect these temperature measurements well: the average surface temperature is roughly $1.5 \mathrm{~K}$ higher than the average air temperature for both soils. Hence, the use of the "equivalent temperature" should be avoided in foundation heat loss calculations, since only the generally positive radiation terms $\left(R_{t}\right)$ are included without the dampening influence of evaporation $(E)$. Average surface temperatures of calculations A and B agree far better with air temperature, 
Postprint: Janssen H, Carmeliet J, Hens $\mathrm{H}$ 2002. The influence of soil moisture in the unsaturated zone on the heat loss from buildings via the ground, Journal of Thermal Envelope and Building Science, 25:275-296.

doi: $10.1177 \% 2 F 0075424202025004683$

and furthermore, they are almost equal. The net addition of "surface" heat by inclusion of the short and long wave radiation terms is indeed compensated by heat loss through evaporation. As the average surface temperatures in the coupled and the linear calculations are equal, they cannot explain for the observed differences between the coupled and the linear heat losses.

When examining the amplitudes, calculations A seem to correspond most to the results of Kusuda and Achenbach (1965) and Givoni and Katz (1985): the resulting surface temperature amplitudes are slightly bigger than that of air temperature. The reverse is true for calculations B. Far more meaningful however is the difference between A and B: the A amplitudes are 20 to $25 \%$ bigger than those in B. Assuming equal thermal permeances for the soil domain, the coupled calculation will result in a 20 to $25 \%$ higher peak value in heat loss. This gives rise to a first major source of deviation between the fully coupled and linear calculation of ground heat loss: a difference in the driving force, the soil surface temperature.

\section{Storage and transfer of heat in the ground domain}

\section{Introduction.}

Apart from different soil surface temperatures, the deviations between the coupled and linear calculations are also brought about by differences in the storage and transfer of heat in the soil medium. This can be seen in Table $2 \mathrm{~b}$ : $\mathrm{U}^{\prime}$ and $\mathrm{L}_{\mathrm{p}}$ ' are very similar for calculations $\mathrm{B}$ and $\mathrm{C}$, whereas considerable disagreements arise when comparing $\mathrm{B} / \mathrm{C}$ to $\mathrm{A}$. Two important causes can be named for the disparate mechanisms for storage and transfer of soil heat in the coupled and the linear calculations:

- the variation of the thermal properties due to the variation of the moisture content during the year leads to different temperature fields and hence to different $U$ '- and $\mathrm{L}_{\mathrm{p}}$ '-factors;

- the flow and storage of sensible and latent heat by transfer, storage and phase change of moisture introduces additional heat transfer and storage mechanisms;

To distinguish between both reasons, additional simulations on the insulated basement in the sand and loam soil were performed. In these additional simulations, the focus lays on the heat transfer equation, and hence, the moisture transfer equation is not solved explicitly. Instead, daily moisture contents, obtained in calculation A, were imposed. The surface heat balance was assumed to be driven by a harmonically varying air temperature (average: $282.61 \mathrm{~K}$, amplitude: $8.14 \mathrm{~K}$ ) with a constant transfer coefficient of $23 \mathrm{~W} / \mathrm{m}^{2} \mathrm{~K}$. This simplification was made to obtain less fluctuating heat loss curves, which makes the display of the results notably clearer.

In a simplified representation, the fully coupled transfer of soil heat can be described as:

$$
\begin{gathered}
{\left[\mathrm{C}+\mathrm{A} \frac{\partial \theta}{\partial \mathrm{T}}+\mathrm{B} \frac{\partial \rho_{\mathrm{v}}}{\partial \mathrm{T}}\right] \frac{\partial \mathrm{T}}{\partial \mathrm{t}}+\left[\mathrm{A}^{\prime \prime} \frac{\partial \theta}{\partial \psi}+\mathrm{B}^{\prime \prime} \frac{\partial \rho_{\mathrm{v}}}{\partial \psi}\right] \frac{\partial \psi}{\partial \mathrm{t}}=} \\
\nabla\left[\left(\lambda *+\beta \frac{\partial \rho_{\mathrm{V}}}{\partial \mathrm{T}}\right) \nabla \mathrm{T}+\left(\alpha^{\prime \prime} \frac{\partial \theta}{\partial \mathrm{T}}+\beta^{\prime \prime} \frac{\partial \rho_{\mathrm{V}}}{\partial \psi}\right) \nabla \psi\right]+\text { gravity } \quad(\theta \text { variable }) \\
\left(\lambda *+\beta \frac{\partial \rho_{\mathrm{V}}}{\partial \mathrm{T}}\right)=\lambda
\end{gathered}
$$

In the set of additional simulations that was performed, the degree of coupling in the equation for heat transfer was stepwise increased. An overview of this evolution is given in Table 3. Calculation D represents the bare minimum: year-averaged moisture contents were imposed, and only conduction was considered as heat transfer mechanism. In this case, $\lambda^{*}-$ and not the effective thermal conductivity $\lambda$ - is applied, to establish an unaffected standard for the 
Postprint: Janssen H, Carmeliet J, Hens $\mathrm{H}$ 2002. The influence of soil moisture in the unsaturated zone on the heat loss from buildings via the ground, Journal of Thermal Envelope and Building Science, 25:275-296.

doi: $10.1177 \% 2 F 0075424202025004683$

assessment of the effect of heat storage and transfer by storage, transfer or phase change of soil moisture. The resulting heat flows are depicted in Figure 6. As the results are most clear for the floor, only those have been retained for further analysis, since the differences in the wall heat losses were less striking.

\section{Latent heat transfer by thermal vapour diffusion.}

In calculations of heat transfer in soil, generally the effective thermal conductivity $\lambda$ is used, instead of the standard thermal conductivity $\lambda^{*}$, hence implicitly including latent heat transfer by vapour diffusion (the $\beta$-term) in standard calculations. This was also done for calculations $\mathrm{B}$ and $\mathrm{C}$. Hence, when comparing those to A, calculation D cannot be assumed the reference. To avoid misinterpretations, the effect of the $\beta$-term is studied apart here - in calculation $\mathrm{E}-$, though it is, strictly speaking, part of the second class of coupling effects studied in this paragraph: heat flow and storage by transfer, storage and phase change of moisture.

As can be seen in Figure 6, this addition has a strong influence on the floor heat losses. This needs to be no surprise, as latent heat transfer by thermal vapour diffusion can, at the moisture contents encountered here, add up to $5 \%$ to the thermal conductivity of soil at a temperature of $283.15 \mathrm{~K}$ and up to $10 \%$ at a temperature of $293.15 \mathrm{~K}$.

\section{Variation of the thermal properties.}

In calculation $\mathrm{F}$, the possible influence of fluctuating thermal properties was analysed. To do so, calculation $\mathrm{E}$ was repeated, but this time with varying moisture contents imposed. In the more abstract case where the thermal conductivity is highest in winter and lowest in summer, one expects an increase of both the average and the amplitude of the heat loss. Our case is not that simple: as can be observed in Figure 4, the soil moisture content - and hence the thermal conductivity - near to the surface is indeed highest in winter, but deeper in the soil, maximum moisture contents occur in the summer.

However, an analysis of the one-dimensional results showed that the variation of the overall thermal resistance of the soil domain - from the surface up to a certain depth - is determined mainly by the layer near to the surface. Hence, in winter the ground domain is thermally less resistant than in summer.

The results of calculation $\mathrm{F}$ are shown in Figure 6: a slight rise in both average and amplitude of the floor heat losses can be observed. This identifies a first source for the differences in the thermal permeances: the variation of thermal properties with moisture content.

\section{Transfer and storage of heat by transfer, storage and phase change of moisture.}

In the part above, the attention was focussed on the coupling mechanisms directly affecting the thermal properties of soil: latent heat transfer by thermal vapour diffusion, and variation of the thermal properties with moisture content. It was shown that both these particular coupling effects contribute to the influence of soil moisture on building heat loss via the ground.

In this part, the other class of coupling mechanisms will be scrutinised: the additional storage and transfer of heat by storage, transfer and phase change of moisture. Strictly speaking, the latent heat transfer by thermal vapour diffusion $(\beta$-term) should be considered here too. For reasons given above, this phenomenon has already been treated.

Three more simulations were performed. In an additional calculation $\mathrm{F}$ bis, the other terms for the storage and transfer of heat in the vapour phase ( $\beta$ "-term, B- \& B"-term) were added: no perceptible influence on the floor heat loss could be noticed. The influence of the vapour phase on the heat transfer in soil hence remains hence restricted to the effect of latent heat transfer by thermal vapour diffusion. 
Postprint: Janssen H, Carmeliet J, Hens $\mathrm{H}$ 2002. The influence of soil moisture in the unsaturated zone on the heat loss from buildings via the ground, Journal of Thermal Envelope and Building Science, 25:275-296.

doi: $10.1177 \% 2 F 0075424202025004683$

In calculation $\mathrm{G}$, the transfer of sensible heat by moisture transfer in the liquid phase ( $\alpha$ "-term $\&$ gravity) is added to the heat transfer equation. The addition of this particular heat transfer mechanism gives rise to an important increase of the average and amplitude of the heat loss (see Figure 6). In calculation $\mathrm{H}$, storage of sensible heat by changes in liquid water content is added to the equations (A- \& A"-term): a significant attenuation of the amplitude of the heat losses is observed. Conclusively, a second important reason for the differences between the coupled and linear thermal permeances is made up by the storage and transfer of sensible heat by the storage and transfer of liquid moisture.

\section{CONCLUSIONS}

In this paper, a fully coupled analysis of basement heat losses has been performed, which has been compared with results from the commonly used linear approach. That way, a generally accepted postulate in the research field of building heat loss via the ground has been falsified: the coupling with soil moisture transfer is indeed not negligible in calculations of foundation heat loss.

A first set of calculations revealed that the fully coupled calculations result in generally higher basement heat losses than the linear calculation, while the use of the "equivalent temperature" resulted in too low heat losses. In a more detailed study, the possible causes for the difference between the coupled and linear calculations have been scrutinised. It has been demonstrated that these fall apart in two main categories: differences in (1) the surface temperature as the driving force, and (2) the mechanisms for storage and transfer of soil heat.

The analysis of the surface temperatures exposed a first important source for deviations: the amplitude of the surface temperature was considerably higher in coupled calculation A than in the linear calculation B. It was also shown that the surface temperatures of A agree well with trends documented in literature: average surface temperature close to average air temperature, and surface temperature amplitude slightly bigger than that of air temperature. Moreover, it was demonstrated that the use of the equivalent temperature, thus omitting evaporation from the surface heat balance, can lead to serious underestimations of the heat losses.

In the examination of the mechanisms for the storage and transfer of soil heat, a preparatory calculation showed that the latent heat transfer by thermal vapour diffusion has a significant influence on foundation heat loss, which is however generally implicitly included in standard calculations by use of an effective thermal conductivity $\lambda$.

The variation of the thermal properties with moisture content was identified a second source for the differences in foundation heat loss resulting from coupled and linear calculations. Due to a decrease in the soil thermal resistance in winter, and its increase in summer, an overall rise of the heat losses was observed. The storage and transfer of soil heat in the vapour phase does not take part in the coupling process: no substantial influence could be noticed. Finally, it was demonstrated that the remaining part of the differences between the coupled and linear calculations must be attributed to the storage and transfer of sensible heat in the liquid phase.

As only one construction and two soil types could be taken into account for this analysis, the aim has never been to fully quantify the examined effects. The aim of this study was to test the hypothesis generally accepted in the field of ground heat loss: the coupling of soil heat transfer with soil moisture does not have a significant effect on the heat losses from buildings via the ground. In this work it has been clearly shown that this hypothesis does not hold: soil moisture does indeed significantly affect the problem of ground heat loss. Comparing it to the uncertainties present in the material properties though, or to the complete heat loss budget of a whole building, puts this particular effect back into perspective. 
Postprint: Janssen $\mathrm{H}$, Carmeliet J, Hens $\mathrm{H}$ 2002. The influence of soil moisture in the unsaturated zone on the heat loss from buildings via the ground, Journal of Thermal Envelope and Building Science, 25:275-296.

doi: $10.1177 \% 2 F 0075424202025004683$

\section{NOMENCLATURE}

C : volumetric thermal capacity $\left(\mathrm{J} / \mathrm{m}^{3} \cdot \mathrm{kg}\right)$

$\mathrm{c}_{1} \quad:$ specific heat of water $(\mathrm{J} / \mathrm{kg} \cdot \mathrm{K})$

$\mathrm{c}_{\mathrm{a}} \quad:$ specific heat of air $(\mathrm{J} / \mathrm{kg} \cdot \mathrm{K})$

$\mathrm{D}_{\mathrm{Tv}} \quad$ : thermal vapour diffusivity $(\mathrm{m} / \mathrm{s})$

$\mathrm{D}_{\psi \mathrm{v}} \quad$ : hydraulic vapour diffusivity $(\mathrm{m} / \mathrm{s})$

E : amount of evaporation $\left(\mathrm{kg} / \mathrm{m}^{2} \cdot \mathrm{s}\right)$

$\mathrm{H}$ : heat exchange by convection $\left(\mathrm{W} / \mathrm{m}^{2}\right)$

HP : heat supply by precipitation $\left(\mathrm{W} / \mathrm{m}^{2}\right)$

$\mathrm{K} \quad$ : hydraulic conductivity $(\mathrm{m} / \mathrm{s})$

k : von Karman constant

$\mathrm{L} \quad$ : heat of vaporisation of water $(\mathrm{J} / \mathrm{kg})$

$\mathrm{L}_{0} \quad: \mathrm{L}$ at $\mathrm{T}_{0}(\mathrm{~J} / \mathrm{kg})$

LE : heat exchange by evaporation $\left(\mathrm{W} / \mathrm{m}^{2}\right)$

$\mathrm{n} \quad$ : porosity (-)

$\mathrm{P} \quad$ : amount of precipitation $\left(\mathrm{kg} / \mathrm{m}^{2} \cdot \mathrm{s}\right)$

$\mathrm{q}_{\mathrm{m}} \quad$ : moisture flux $(\mathrm{kg} / \mathrm{s})$

$\mathrm{q}_{\mathrm{h}, \mathrm{se}} \quad$ : heat flow into soil $\left(\mathrm{W} / \mathrm{m}^{2}\right)$

$\mathrm{q}_{\mathrm{m}, \mathrm{se}} \quad:$ water drainage into the soil $\left(\mathrm{kg} / \mathrm{m}^{2} \cdot \mathrm{s}\right)$

$\mathrm{r}_{\mathrm{a}} \quad$ : aerodynamic resistance $(\mathrm{s} / \mathrm{m})$

$\mathrm{R}_{\mathrm{t}} \quad$ : net radiation $\left(\mathrm{W} / \mathrm{m}^{2}\right)$

$\mathrm{R}_{\mathrm{g}} \quad$ : long wave surface emission $\left(\mathrm{W} / \mathrm{m}^{2}\right)$

$\mathrm{R}_{\text {glob }} \quad$ : short wave radiation $\left(\mathrm{W} / \mathrm{m}^{2}\right)$

$\mathrm{R}_{\text {sky }} \quad$ : long wave sky irradiance $\left(\mathrm{W} / \mathrm{m}^{2}\right)$

$\mathrm{t} \quad$ : time (s)

$\mathrm{T} \quad$ : temperature $(\mathrm{K})$

$\mathrm{T}_{0} \quad:$ reference temperature $(\mathrm{K})$

$\mathrm{T}_{\mathrm{e}} \quad$ : air temperature $(\mathrm{K})$

$\mathrm{T}_{\mathrm{se}} \quad$ : surface temperature $(\mathrm{K})$

$\mathrm{W} \quad$ : heat of wetting $(\mathrm{J} / \mathrm{kg})$

Ws $\quad$ : wind speed $(\mathrm{m} / \mathrm{s})$

$\mathrm{z} \quad$ : depth (m) (downward positive)

$\mathrm{z}_{\mathrm{a}} \quad$ : wind measuring height $(\mathrm{m})$

$\mathrm{Z}_{0} \quad$ : roughness length $(\mathrm{m})$

$\alpha \quad$ : soil surface albedo (-)

$\varepsilon_{\mathrm{g}} \quad:$ emissivity of ground surface (-)

$\theta \quad:$ moisture content $\left(\mathrm{m}^{3} / \mathrm{m}^{3}\right)$

$\lambda \quad$ : effective thermal conductivity $(\mathrm{W} / \mathrm{m} \cdot \mathrm{K})$

$\lambda^{*} \quad:$ "pure" thermal conductivity $(\mathrm{W} / \mathrm{m} \cdot \mathrm{K})$

$\rho_{1} \quad:$ liquid density $\left(\mathrm{kg} / \mathrm{m}^{3}\right)$

$\rho_{\mathrm{v}} \quad$ : vapour density $\left(\mathrm{kg} / \mathrm{m}^{3}\right)$

$\rho_{\mathrm{a}} \quad:$ density of air $\left(\mathrm{kg} / \mathrm{m}^{3}\right)$

$\rho_{\mathrm{v}, \mathrm{e}} \quad:$ vapour density in air $\left(\mathrm{kg} / \mathrm{m}^{3}\right)$

$\rho_{\mathrm{v}, \mathrm{se}} \quad$ : surface vapour density $\left(\mathrm{kg} / \mathrm{m}^{3}\right)$

$\sigma \quad$ : Boltzman constant 
Postprint: Janssen H, Carmeliet J, Hens $\mathrm{H}$ 2002. The influence of soil moisture in the unsaturated zone on the heat loss from buildings via the ground, Journal of Thermal Envelope and Building Science, 25:275-296.

doi: $10.1177 \% 2 F 0075424202025004683$

$\phi \quad$ : instability factor (-)

$\psi \quad$ : matric potential $(\mathrm{m})$

\section{REFERENCES}

Anderson E.A., 1976. A point energy and mass balance of a snow cover, NOAA Technical Report NWS 19, Silver Spring, United States.

Anderson, B.R. 1991. "Calculation of the steady-state heat transfer through a slab-on-ground floor", Building and Environment, 26:405-415.

Anderson, B.R. 1993. "The effect of edge insulation on the steady-state heat transfer through a slab-on-ground floor", Building and Environment, 28:361-367.

Bahnfleth, W.P. and C.O. Pedersen, 1990. "A three-dimensional numerical study of slab-ongrade heat transfer", ASHRAE Transactions, 96:61-72.

Bareither, H.D., A.N.Fleming and B.E. Alberty. 1948. Temperature and heat loss characteristics of concrete floors laid on the ground. Technical Report PB 93920, Small Homes Council, University of Illinois.

Bharadwaj, S.S., and N.K. Bansal. 1981. "Temperature distribution inside ground for various surface conditions", Building and Environment, 16:183-192.

Delsante, A.E. 1993. "The effect of water table depth on steady-state heat transfer through a slab-on-ground floor", Building and Environment, 28:369-372.

de Vries, D.A. 1958. "Simultaneous transfer of heat and moisture in porous media", Transactions American Geophysical Union, 39:909-916.

Dill, R.S., W.C. Robinson, and H.E. Robinson. 1945. Measurements of heat losses from slab floors. Building Materials and Structures Report BMS 103, Nat. Bur. Stds., U.S. Dept. of Commerce.

Farouki, O.T. 1982. Evaluation of methods for calculating soil thermal conductivity. CRREL Report 82-8, United States.

Givoni B., and L. Katz. 1985. "Earth temperatures and underground buildings", Energy and Buildings, 8:15-25.

Gupta, S.C., J.K. Radke, and W.E. Larson. 1981. "Predicting temperature of bare and residue covered soils with and without a corn crop", Soil Sci. Soc. Am. J., 45:405-412.

Hagentoft, C.-E. 1988. Heat loss to the ground from a building. Ph.D. thesis, Lund University of Technology.

Hagentoft, C.-E. 1996. "Heat losses and temperature in the ground under a building with and without ground water flow-II. Finite ground water flow rate", Building and Environment, 31:13-19.

Houghten, F.C., S.K. Taimuty, C. Guberlet, and C.J. Brown. 1942. "Heat loss through basement walls and floors". Heating, Piping and Air-Conditioning, 14:69-74.

Janssen, H., J. Carmeliet, and H. Hens. 1999. "A numerical model for the coupled heat and moisture transfer in homogeneous soils". Proceedings of "International workshop on Modelling of transport processes in soils at various scales”, 24-26 November 1999, Leuven, Belgium.

Kusuda T., and P.R. Achenbach. 1965. "Earth temperature and thermal diffusivity at selected stations in the United States", ASHRAE Transactions, 71:61-75.

Matsumoto, M.; and A. Iwamae. 1988. "An analysis of temperature and moisture variation in the ground under natural climatic conditions", Energy and Buildings, 11:221-237.

Milly, P.C.D. 1980. The coupled transport of water and heat in a vertical soil column under atmospheric excitation. Ph.D. thesis, Massachusetts Institute of Technology, Massachusetts. 
Postprint: Janssen H, Carmeliet J, Hens $\mathrm{H}$ 2002. The influence of soil moisture in the unsaturated zone on the heat loss from buildings via the ground, Journal of Thermal Envelope and Building Science, 25:275-296.

doi: $10.1177 \% 2 F 0075424202025004683$

Ogura D., T. Matsushita and M. Matsumoto. 1995. "A study of heat and moisture behavior of an underground space - effects of wall structure -", Proceedings of the International Symposium on Moisture Problems in Building Walls, pp. 22-31, 11-13 September 1995, Porto, Portugal.

Ogura D., H. Nagai, T. Matsushita and M. Matsumoto. 1998. "An analysis of heat and moisture behavior in underground space by quasi-linearized method", Proceedings of the CIB-W40 Meeting, Publication 213, pp. 313-328, Kyoto, Japan.

Philip, J.R., and D.A. de Vries. 1957. "Moisture movement in porous materials under temperature gradients", Transactions American Geophysical Union, 38:222-232.

Rees, S.W., Z. Zhou and H.R. Thomas. 2001. "The influence of soil moisture content variations on heat losses from earth-contact structures: an initial assessment". Building and Environment, 36:157-165.

Schaap, M.G., F.J. Leij, and M.Th. van Genuchten. 1998. "Neural network analysis for hierarchical prediction of soil hydraulic properties", Soil Sci. Soc. Am. J., 62:847-855.

Shen, L.S. 1986. An investigation of transient, two-dimensional coupled heat and moisture flow in soils. Ph.D. thesis, University of Minnesota, United States.

Tarnawski, V.R., B. Wagner, J. Webber and L. Pettipas. 1997. "Optimization of soil mineralogical composition for predicting soil thermal conductivity", Proceedings of the international symposium on Physics, Chemistry, and Ecology of Seasonally Frozen Soils, June 10-12 1997, Fairbanks, Alaska. 
Postprint: Janssen H, Carmeliet J, Hens $\mathrm{H}$ 2002. The influence of soil moisture in the unsaturated zone on the heat loss from buildings via the ground, Journal of Thermal Envelope and Building Science, 25:275-296.

doi: $10.1177 \% 2 F 0075424202025004683$

Table 1a. Year-averaged heat losses for calculations $A, B$ and $C$

\begin{tabular}{lcccc}
\hline & \multicolumn{2}{c}{ Sand } & \multicolumn{2}{c}{ Loam } \\
Calculation & Floor $(\mathrm{W})$ & Wall $(\mathrm{W})$ & Floor $(\mathrm{W})$ & Wall $(\mathrm{W})$ \\
\hline A & 11.07 & 12.25 & 10.06 & 11.90 \\
B & 10.24 & 11.54 & 9.16 & 11.05 \\
C & 8.63 & 9.80 & 7.79 & 9.47 \\
\hline
\end{tabular}

Table $1 b$. Heating season net energy demands for calculations $A, B$ and $C$

\begin{tabular}{lcccc}
\hline & \multicolumn{2}{c}{ Sand } & \multicolumn{2}{c}{ Loam } \\
Calculation & Floor $(\mathrm{MJ})$ & Wall $(\mathrm{MJ})$ & Floor $(\mathrm{MJ})$ & Wall $(\mathrm{MJ})$ \\
\hline A & 170.8 & 254.4 & 154.7 & 240.9 \\
B & 158.5 & 229.7 & 141.4 & 217.6 \\
C & 134.4 & 229.4 & 120.5 & 217.5 \\
\hline
\end{tabular}

Table 2a. Averages and amplitudes of surface temperatures for calculations $A, B$ and $C$

\begin{tabular}{lcccc}
\hline & \multicolumn{2}{c}{ Sand } & \multicolumn{2}{c}{ Loam } \\
Calculation & Average $(\mathrm{K})$ & Amplitude $(\mathrm{K})$ & Average $(\mathrm{K})$ & Amplitude $(\mathrm{K})$ \\
\hline Air temperature & 282.61 & 8.14 & 282.61 & 8.14 \\
A & 282.42 & 9.30 & 282.29 & 9.17 \\
B & 282.46 & 7.53 & 282.45 & 7.54 \\
C & 284.12 & 10.60 & 284.03 & 10.57 \\
\hline
\end{tabular}

Table $2 b$. Steady state and periodic thermal permeances for calculations $A, B$ and $C$

\begin{tabular}{lcccccccc}
\hline \multirow{2}{*}{ Calculation } & \multicolumn{4}{c}{ Sand } & \multicolumn{5}{c}{ Loam } \\
& \multicolumn{2}{c}{$\mathrm{U}^{\prime}\left(\mathrm{W} / \mathrm{m}^{2} \mathrm{~K}\right)$} & \multicolumn{2}{c}{$\mathrm{L}_{\mathrm{p}}{ }^{\prime}\left(\mathrm{W} / \mathrm{m}^{2} \mathrm{~K}\right)$} & \multicolumn{2}{c}{$\mathrm{U}^{\prime}\left(\mathrm{W} / \mathrm{m}^{2} \mathrm{~K}\right)$} & \multicolumn{2}{c}{$\mathrm{L}_{\mathrm{p}}{ }^{\prime}\left(\mathrm{W} / \mathrm{m}^{2} \mathrm{~K}\right)$} \\
A & Floor & Wall & Floor & Wall & Floor & Wall & Floor & Wall \\
B & 0.206 & 0.457 & 0.021 & 0.318 & 0.185 & 0.438 & 0.016 & 0.293 \\
C & 0.191 & 0.432 & 0.026 & 0.326 & 0.171 & 0.413 & 0.019 & 0.304 \\
\hline
\end{tabular}

Table 3. Degree of coupling between heat and moisture transfer in the additional simulations $D-H$.
$\mathrm{D} \quad \mathrm{C} \frac{\partial \mathrm{T}}{\partial \mathrm{t}}=\nabla[\lambda * \nabla \mathrm{T}] \quad(\vartheta$ fixed)
E $\quad \mathrm{C} \frac{\partial \mathrm{T}}{\partial \mathrm{t}}=\nabla\left[\left(\lambda *+\boldsymbol{\beta} \frac{\partial \boldsymbol{\rho}_{\mathbf{v}}}{\partial \mathbf{T}}\right) \nabla \mathrm{T}\right] \quad(\vartheta$ fixed $) \quad \lambda^{*}+\beta \frac{\partial \rho_{\mathbf{v}}}{\partial \mathrm{T}}=\lambda$
$\mathrm{F} \quad \mathrm{C} \frac{\partial \mathrm{T}}{\partial \mathrm{t}}=\nabla\left[\left(\lambda *+\beta \frac{\partial \rho_{\mathrm{v}}}{\partial \mathrm{T}}\right) \nabla \mathrm{T}\right] \quad(\vartheta$ variable $)$
F bis $\left[\mathrm{C}+\mathbf{B} \frac{\partial \boldsymbol{\rho}_{\mathbf{v}}}{\partial \mathbf{T}}\right] \frac{\partial \mathrm{T}}{\partial \mathrm{t}}+\left[\mathbf{B}^{\prime \prime} \frac{\partial \boldsymbol{\rho}_{\mathbf{v}}}{\partial \boldsymbol{\psi}}\right] \frac{\partial \psi}{\partial \mathrm{t}}=\nabla\left[\left(\lambda *+\beta \frac{\partial \rho_{\mathbf{V}}}{\partial \mathrm{T}}\right) \nabla \mathrm{T}+\left(\boldsymbol{\beta}^{\prime \prime} \frac{\partial \boldsymbol{\rho}_{\mathbf{v}}}{\partial \boldsymbol{\psi}}\right) \nabla \psi\right]$ 
Postprint: Janssen H, Carmeliet J, Hens $\mathrm{H}$ 2002. The influence of soil moisture in the unsaturated zone on the heat loss from buildings via the ground, Journal of Thermal Envelope and Building Science, 25:275-296.

$\mathrm{G} \quad\left[\mathrm{C}+\mathrm{B} \frac{\partial \rho_{\mathrm{V}}}{\partial \mathrm{T}}\right] \frac{\partial \mathrm{T}}{\partial \mathrm{t}}+\left[\mathrm{B}^{\prime \prime} \frac{\partial \rho_{\mathrm{V}}}{\partial \psi}\right] \frac{\partial \psi}{\partial \mathrm{t}}=$

$$
\nabla\left[\left(\lambda *+\beta \frac{\partial \rho_{\mathrm{v}}}{\partial \mathrm{T}}\right) \nabla \mathrm{T}+\left(\boldsymbol{\alpha}^{\prime \prime} \frac{\partial \vartheta}{\partial \psi}+\beta^{\prime \prime} \frac{\partial \rho_{\mathrm{v}}}{\partial \psi}\right) \nabla \psi\right]+\text { gravity }
$$

$\mathrm{H} \quad\left[\mathrm{C}+\mathbf{A} \frac{\partial \vartheta}{\partial \mathbf{T}}+\mathrm{B} \frac{\partial \rho_{\mathrm{V}}}{\partial \mathrm{T}}\right] \frac{\partial \mathrm{T}}{\partial \mathrm{t}}+\left[\mathbf{A}^{\prime \prime} \frac{\partial \vartheta}{\partial \boldsymbol{\psi}}+\mathrm{B}^{\prime \prime} \frac{\partial \rho_{\mathrm{V}}}{\partial \psi}\right] \frac{\partial \psi}{\partial \mathrm{t}}=$

$$
\nabla\left[\left(\lambda *+\beta \frac{\partial \rho_{\mathrm{V}}}{\partial \mathrm{T}}\right) \nabla \mathrm{T}+\left(\alpha^{\prime \prime} \frac{\partial \vartheta}{\partial \mathrm{T}}+\beta^{\prime \prime} \frac{\partial \rho_{\mathrm{V}}}{\partial \psi}\right) \nabla \psi\right]+\text { gravity }
$$


Postprint: Janssen $\mathrm{H}$, Carmeliet $\mathrm{J}$, Hens $\mathrm{H}$ 2002. The influence of soil moisture in the unsaturated zone on the heat loss from buildings via the ground, Journal of Thermal Envelope and Building Science, 25:275-296.

doi: $10.1177 \% 2 F 0075424202025004683$

FIGURE 1: Dimensions and discretisation of the calculation domain.

FIGURE 2: Water retention curve, hydraulic conductivity, thermal conductivity and specific heat for the sand and loam soil.

FIGURE 3: Monthly averaged air temperature and monthly amounts of rain for the Essen (Germany) climate.

FIGURE 4: Resulting temperature (top) and moisture content (bottom) profiles in the sand and loam soil under the Essen (Germany) climate (monthly averages were calculated, one every two months is shown here).

FIGURE 5: Heat losses through wall and floor for the insulated basement, for the sand (top) and loam (bottom) soil for calculations A, B and C.

FIGURE 6: Heat losses through wall and floor for the insulated basement, for the sand (top) and loam (bottom) soil for calculations D, E, F, G and H. 
Postprint: Janssen H, Carmeliet J, Hens $\mathrm{H}$ 2002. The influence of soil moisture in the unsaturated zone on the heat loss from buildings via the ground, Journal of Thermal Envelope and Building Science, 25:275-296.

\section{FIGURE 1:}

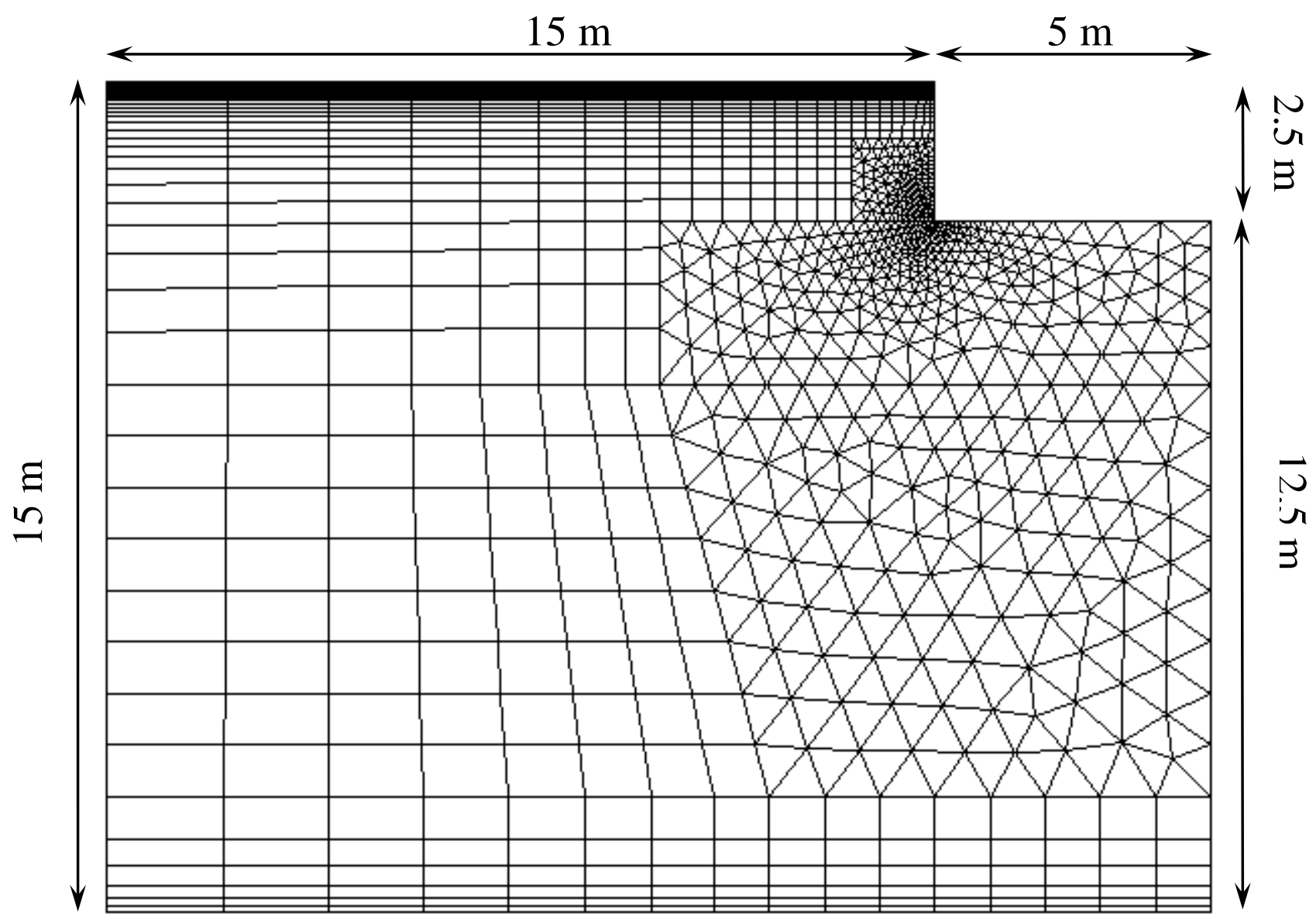


Postprint: Janssen H, Carmeliet J, Hens $\mathrm{H}$ 2002. The influence of soil moisture in the unsaturated zone on the heat loss from buildings via the ground, Journal of Thermal Envelope and Building Science, 25:275-296.

FIGURE 2:
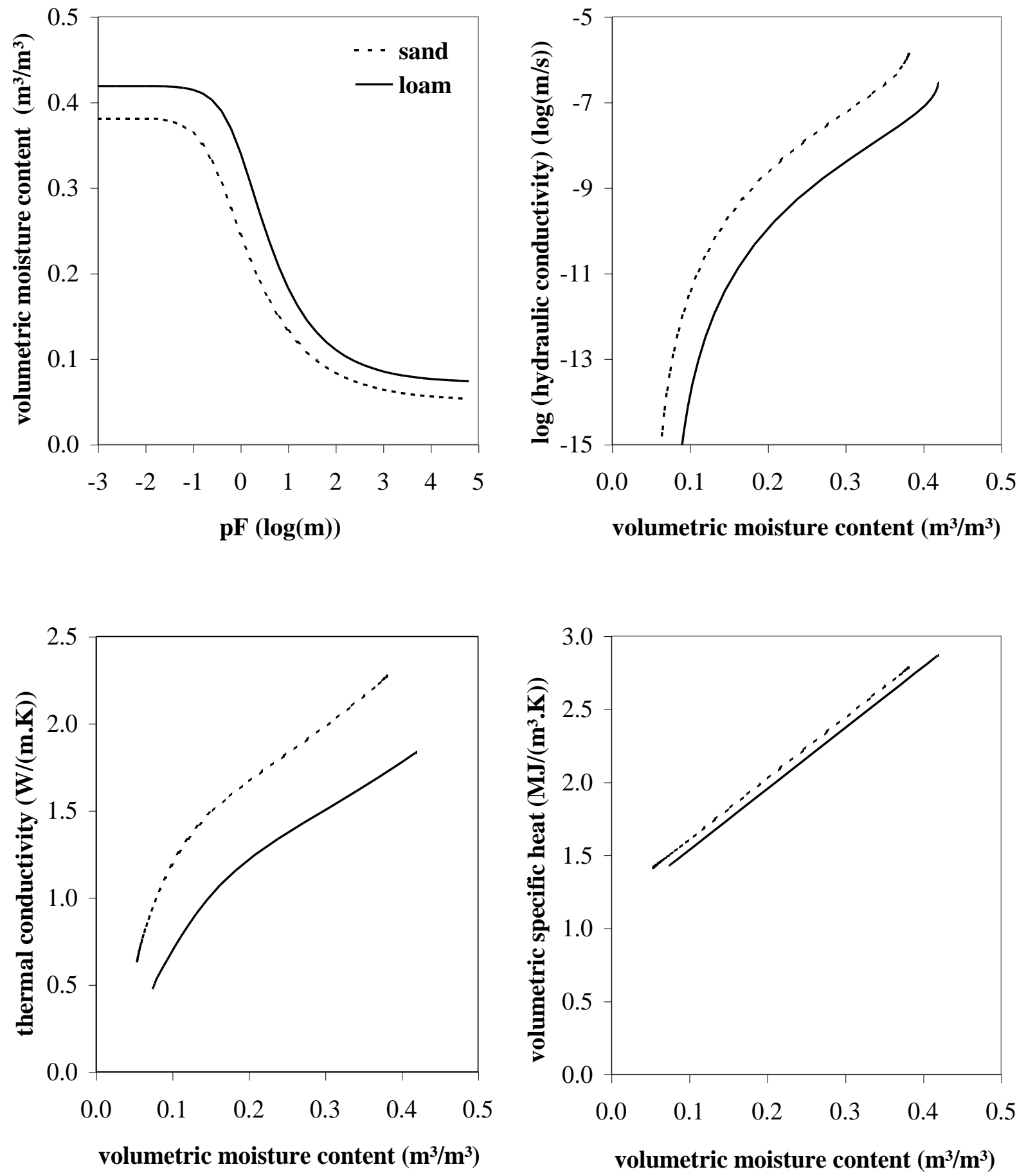
Postprint: Janssen H, Carmeliet J, Hens $\mathrm{H}$ 2002. The influence of soil moisture in the unsaturated zone on the heat loss from buildings via the ground, Journal of Thermal Envelope and Building Science, 25:275-296.

FIGURE 3:

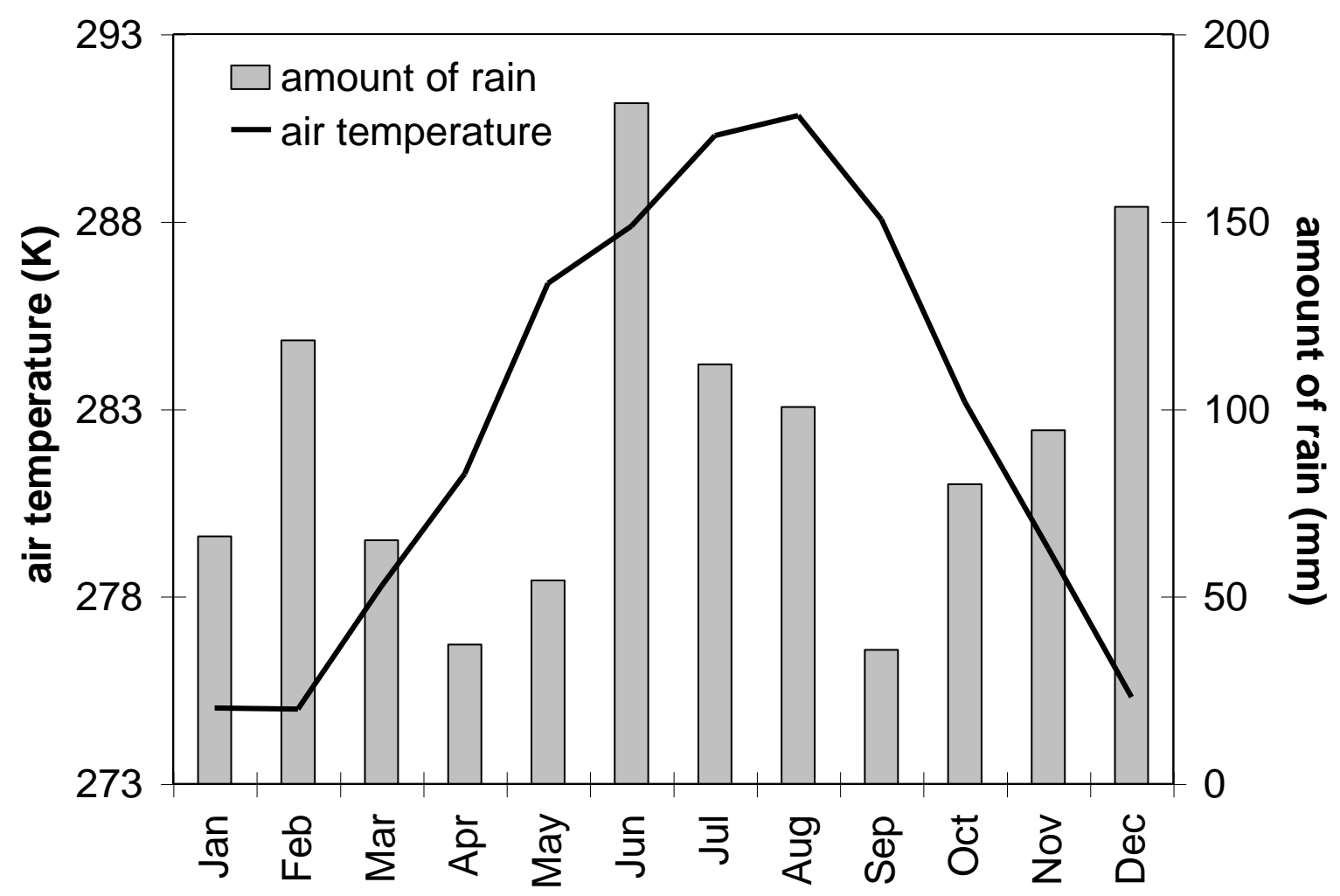


Postprint: Janssen H, Carmeliet J, Hens $\mathrm{H}$ 2002. The influence of soil moisture in the unsaturated zone on the heat loss from buildings via the ground, Journal of Thermal Envelope and Building Science, 25:275-296.

\section{FIGURE 4:}
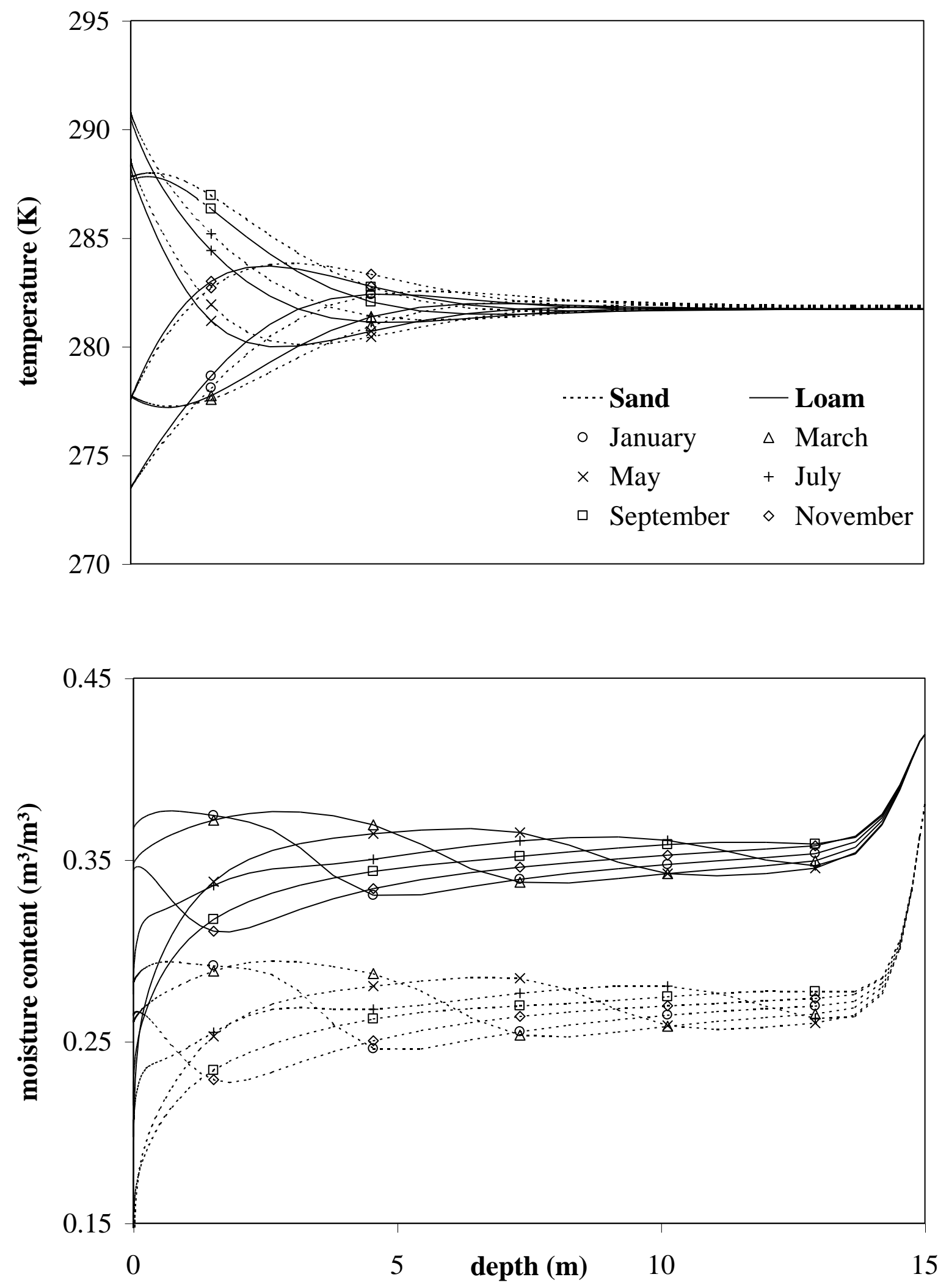
Postprint: Janssen H, Carmeliet J, Hens $\mathrm{H}$ 2002. The influence of soil moisture in the unsaturated zone on the heat loss from buildings via the ground, Journal of Thermal Envelope and Building Science, 25:275-296.

\section{FIGURE 5:}
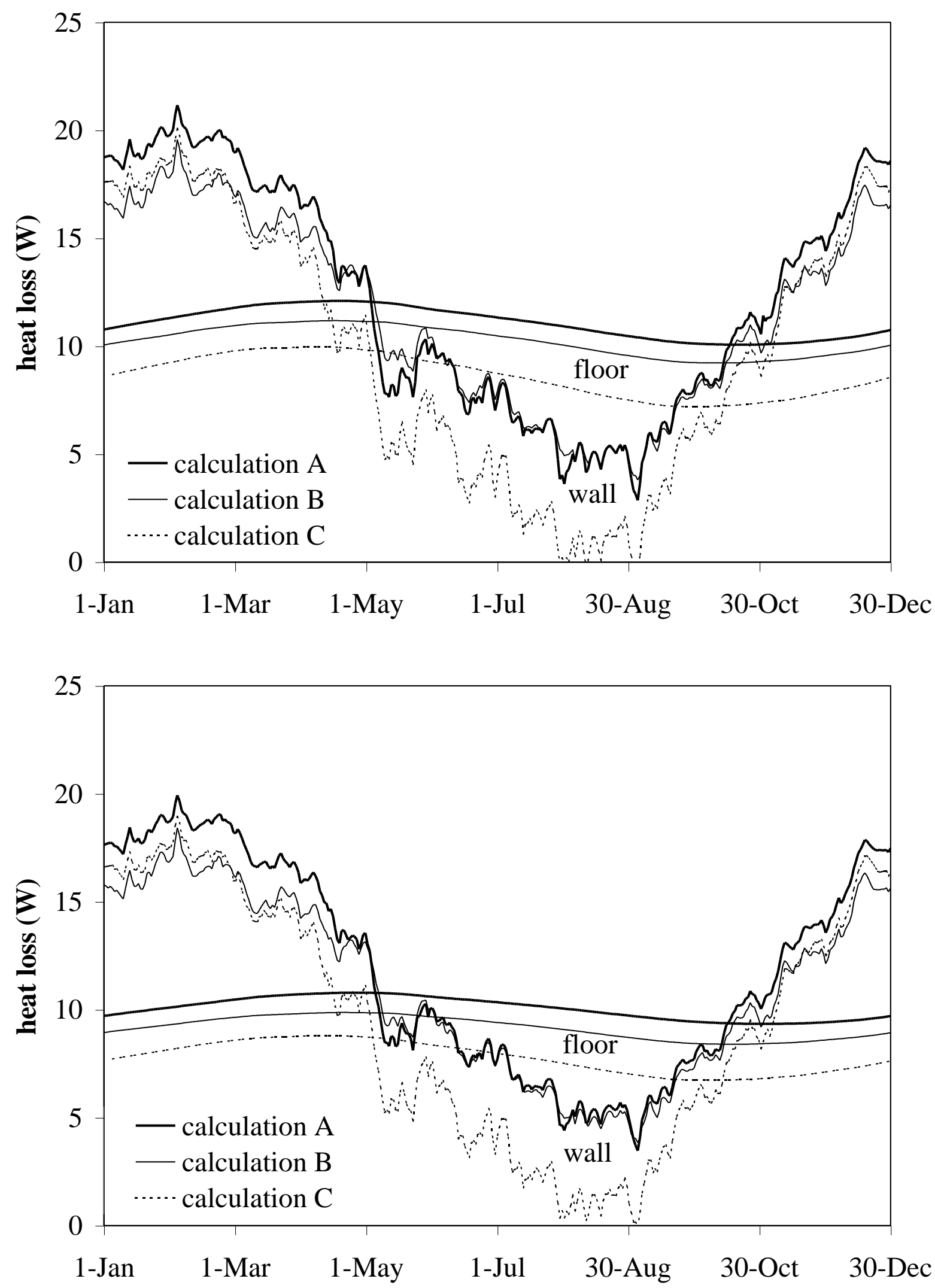

FIGURE 6: 
Postprint: Janssen H, Carmeliet J, Hens $\mathrm{H}$ 2002. The influence of soil moisture in the unsaturated zone on the heat loss from buildings via the ground, Journal of Thermal Envelope and Building Science, 25:275-296.

doi: $10.1177 \% 2 F 0075424202025004683$
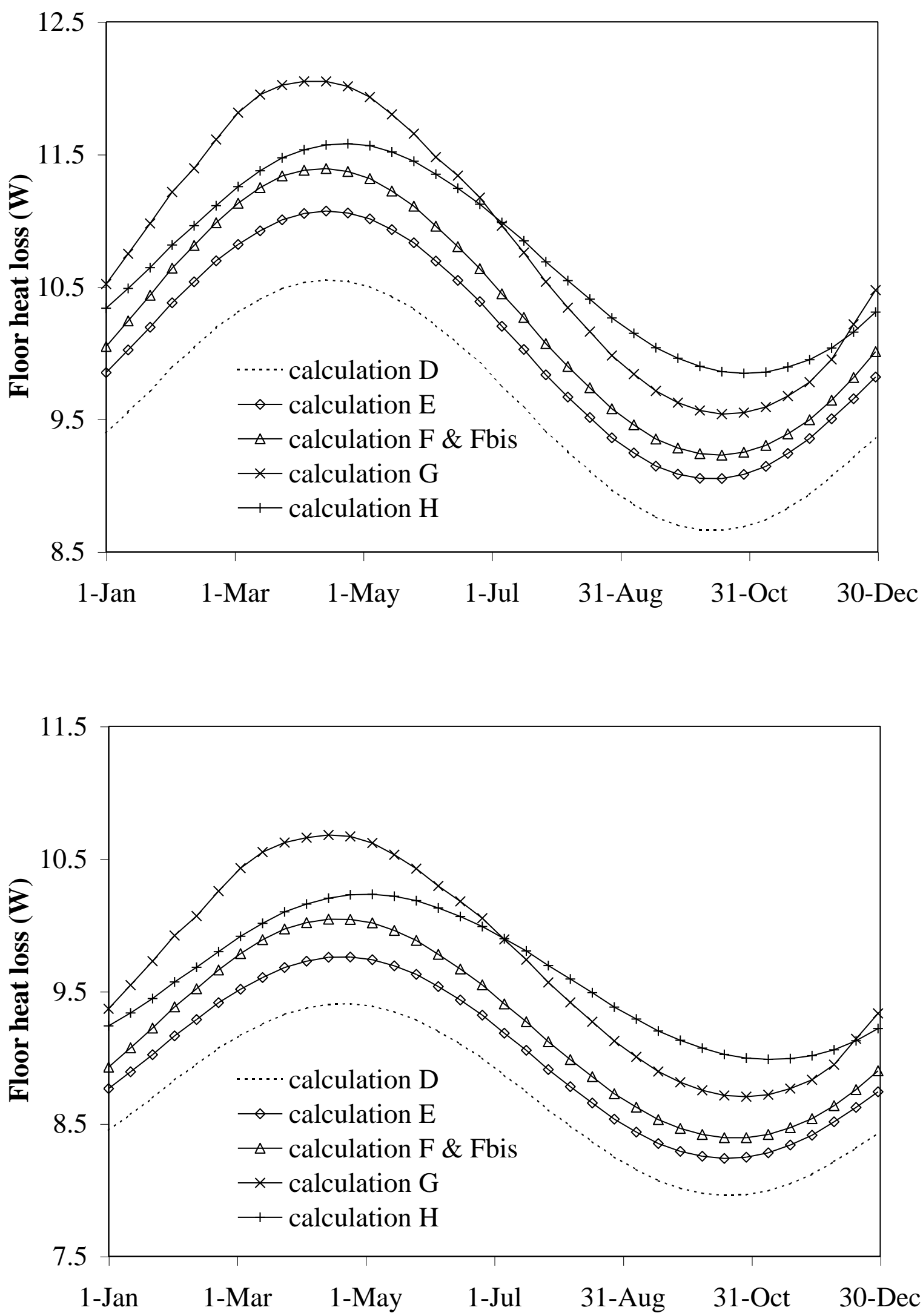
Postprint: Janssen H, Carmeliet J, Hens $\mathrm{H}$ 2002. The influence of soil moisture in the unsaturated zone on the heat loss from buildings via the ground, Journal of Thermal Envelope and Building Science, 25:275-296.

doi: $10.1177 \% 2 F 0075424202025004683$

\section{Biography}

Hans Janssen is a Ph.D. student at the Laboratory of Building Physics, Department of Civil Engineering, Katholieke Universiteit Leuven. His research project is entitled: "The influence of moisture in soil on the heat transfer between buildings and the ground". He graduated at this university in 1997 on the basis of the thesis: "Thermal performance of highly insulated wood frame walls". The research for this thesis was performed at the Norwegian University of Science and Technology in Trondheim, Norway.

Professor Jan Carmeliet earned his Ph.D. at the Katholieke Universiteit Leuven, 1992 with highest distinction, on "Durability of fibre-reinforced renderings for outside insulation: a probabilistic approach based on the non-local continuum damage mechanics". $\mathrm{He}$ is an associated professor teaching Building Engineering, Building Physics and Project Engineering. Since 2001, he is also a professor at the Technical University of Eindhoven, The Netherlands. His research issues are: heat and mass transfer in heterogeneous, cracked, porous building materials; driving rain; durability physics and mechanics; X-ray computer tomography for moisture transfer identification and non-destructive testing of materials.

Professor Hugo Hens is founder and head of the Laboratory of Building Physics, Department of Civil Engineering, Katholieke Universiteit Leuven. He teaches Building Physics, Building Construction and Building Services. He earned his Ph.D. in 1975 at the same university with the dissertation "Theoretical and experimental study of the hygro-thermal behaviour of building and insulating materials during interstitial condensation processes and drying, application on flat roofs.". He is member of several Building Physic related organisations and he wrote 114 papers and 5 books in the field of Building Physics. 